\title{
KARAKTERISASI MELALUI GAYA BAHASA DALAM KUMPULAN CERPEN SENYUM KARYAMIN KARYA AHMAD TOHARI
}

\author{
Endang Sulistijani \\ Pendidikan Bahasa dan Sastra Indonesia, \\ Fakultas Bahasa dan Seni,Universitas Indraprasta PGRI \\ (endang711@yahoo.co.id)
}

\begin{abstract}
ABSTRAK
Tujuan makalah ini adalah memaparkan bentuk telaah karekterisasi melalui gaya bahasa. Penelitian kualitatif ini menggunakan metode content analysis dan pendekatan struktural. Karakterisasi dalam cerita sangat berperan dalam menghidupkan tokoh imajinatif pengarang. Banyak cara dilakukan oleh pengarang dalam menggambarkan karakter tokoh-tokohnya, baik secara langsung ataupun tak langsung. Dengan berbagai macam gaya bahasa, pengarang dapat menggambarkan tokoh imajinatifnya sehingga lebih hidup dan berkesan. Kumpulan cerpen Senyum Karyamin karya Ahmad Tohari bertokoh orang-orang lapisan bawah. Dengan gaya bahasa yang khas, tokoh-tokoh dalam kumpulan cerpen tersebut bukan sekedar pembeberan watak orang kecil yang dibebani oleh masalah kehidupan. Namun, sarat pesan dalam penggambaran wataknya. Misalnya, dengan gaya bahasa ironi kemunafikan manusia dapat digambarkan dengan jelas atau bagaimana seseorang yang congkak digambarkan melalui gaya bahasa metafor yang tajam.
\end{abstract}

Kata Kunci: karakteristik, gaya bahasa, kumpulan cerpen

\section{A. PENDAHULUAN}

Sastra adalah ungkapan pribadi manusia yang berupa pengalaman, pemikiran, perasaan, ide, semangat, keyakinan dalam suatu bentuk gambarankonkret yang membangkitkan pesona dengan alat bahasa (Soemardjo dan Saini, 1986:3). Hakikat material sebuah karya sastra adalah kata. Kata-kata itu harus disusun sedemikian rupa sehingga melalui kegiatan membaca, akan muncul suatu model dunia sosial, model kepribadian individu, dan model interaksi individu dengan dunia sosial. Melalui bahasa, karya sastra dapat menampilkan macam-macam model. Oleh karena itu dalam sebuah karya sastra dapat ditemukan karakter-katakter kehidupan manusia pada masa lampau, masa kini, ataupun masa yang akan datang (Kinayati, 2009:16).

Karakterisasi atau dalam bahasa Inggris charaterization berarti pemeranan, pelukisan watak. Penciptaan tokoh-tokoh dengan karakter yang berbeda menambah hidup suatu cerita. Dalam menampilkan tokoh-tokohnya, pengarang pun dapat menggambarkan karakter tokoh dengan bermacam-macam. 
Lubbock (dalam Aziez \& Hasim, 2010:64)memberikan dua cara fundamental yang digunakan pengarang dalam penciptaan tokoh yaitu dengan cara telling (menceritakan) dan showing (menunjukkan). Hal ini tidak jauh berbeda dengan cara yang dikemukakan Semi (1988) yang menyebutkan ada dua cara memperkenalkan watak tokoh yaitu secara analitik dan secara dramatik. Secara analitik berarti pengarang langsung memaparkan karakter tokoh sedangkan secara dramatik penggambaran watak tidak diceritakan secara langsung tetapi melalui dialog antartokoh, penggambaran fisik tokoh, tingkah laku, interaksi tokoh, dsb.

Menurut Albertine (2005:3), cara melukiskan watak tokoh tidak terbatas pada cara langsung (telling) dan tidak langsung (showing) semata. Namun, di dalam melukiskan tokoh-tokoh cerita baik secara langsung maupun tidak langsung, pengarang dapat menggunakan gaya bahasa (figurative language). Dengan menggunakan gaya bahasa, pemaparan imajinatif menjadi lebih segar dan berkesan.Selain itu dengan gaya bahasa, pembaca tidak bosan dengan pemaparan karakter tokohnya baik secara metaforis, simbolis, atau yang lainnya.

Gaya bahasa atau yang sering disebut dengan majas merupakan pengungkapan bahasa yang maknanya tidak menunjuk pada makna harafiah katakata yang mendukungnya, melainkan pada makna yang ditambahkan atau makna tersirat (Nurgiyantoro, 2014:215). Menurut Nurgiyantoro, majas atau gaya bahasa ini dibagi menjadi kelompok majas perbandingan, pertautan, pengontrasan, dan susunan lain. Gaya bahasa perbandingan meliputi simile, metafora, dan personifikasi. Gaya bahasa pertautan meliputi mitonimi dan sinekdoki sedangkan gaya bahasa pengontrasan meliputi hiperbola, litotes, paradoks, ironi, dan sarkasme (2014:215-269). Gaya bahasa ini sangat banyak digunakan dalam karya sastra baik puisi, cerpen, maupun novel.

Sastra Indonesia merupakan cermin kehidupan masyarakat Indonesia dan identitas bangsa Indonesia. Hal itu mencakup semua genre sastra. Salah satu genre sastra yang tidak membutuhkan waktu lama dalam pembacaan adalah cerpen. Cerpen-cerpen Ahmad Tohari yang terkumpul dalam kumpulan cerpen Senyum Karyamin berjumlah 13 cerpen. Salah satu cerpen yang berjudul Jasa-Jasa buat Sanwirya pernah mendapat hadiah hiburan dalam sayembara Kincir Emas tahun 1975 yang diselenggarakan oleh Radio Nederlands Wereldomroep.Semua karya 
Tohari, baik novel maupun cerpen-cerpennya selalu mengangkat tokoh yang sederhana.

Kesederhanaan karya Tohari terlihat pada tema yang diusung, rangkaian peristiwanya, lingkungan masyarakatnya, latarnya yang jarang dijamah oleh pengarang Indonesia . Misalnya, dunia pedesaan yang lugu dan alami, kaum termarjinalkan yang melarat, miskin, bodoh (mudah dibohongi), dsb. Dengan membaca cerpen-cerpen Ahmad Tohari, dapat ditangkap pesan-pesan bermakna dari kehidupan yang dialami tokoh sentralnya yang berasal dari lingkungan wong cilik. Meskipun mengangkat peristiwa-peristiwa sederhana, pemakaian gaya bahasa seperti metafora, personifikasi, ironi, menguatkan cerita-cerita tersebut.

Menurut Albertine, gaya bahasa mencakup berbagai figur bahasa antara lain metafor, simile, antitesis, hiperbola, dan sebagainya. Gaya bahasa dapat menjelaskan orang atau objek benda lain (2011:51). Dalam tulisan ini akan dibahas gaya bahasa yang menggambarkan karakter tokoh-tokoh cerita dalam kumpulan cerpen Senyum Karyamin karya Ahmad Tohari. Bagaimana pengarang menggambarkan tokoh yang giat berjuang untuk menghidupi keluarganya serta harus kuat menghadapi cobaan hidup, seperti dalam contoh kutipan di bawah ini:

Si paruh udang kembali melintas cepat dengan suara mencecet. Karyamin tak lagi membencinya karena sadar, burung yang demikian sibuk pasti sedang mencari makan buat anak-anaknya dalam sarang entah di mana. Karyamin membayangkan anak-anak si paruh udang sedang meringkuk lemah dalam sarang yang dibangun dalam tanah di sebuah tebing yang terlindung. Angin kembali bertiup. Daun-daun jati beterbangan dan beberapa di antaranya jatuh ke permukaan sungai. Daundaun itu selalu saja bergerak menentang arus karena dorongan angin (Tohari, 2002:4).

Cerpen merupakan salah satu jenis prosa fiksi yang menceritakan sekelumit tentang kehidupan manusia. Meskipun hanya sekelumit kehidupan, pembaca dapat mengambil manfaatnya. Selain memperluas wawasan pengetahuan, mempertajam perasaan, lebih peka terhadap lingkungan, kehidupan manusia, pembaca juga mendapat pelajaran moral atau budi pekerti dari kegiatan 
menbaca karya sastra tersebut. Pembaca dari semua kalangan baik di sekolah maupun di universitas dapat menggunakan cerpen-cerpen ini menjadi bahan diskusi ataupun kajian. Dengan memahami karakter tokoh dari berbagai kalangan seperti kalangan wong cilik dari kumpulan cerpen ini, peserta didik dapat belajar dari kejujuran, apa adanya dan rasa syukur yang dirasakan oleh rakyat kecil.

Penelitian ini adalah penelitian kualitatif dengan menggunakan analisis isi. Pendekatan yang digunakan adalah pendekatan struktural yang ditujukan untuk menganalisis karakter tokoh baik secara langsung ataupun tidak langsung yang digambarkan dalam gaya bahasa.

Pengumpulan data dilakukan dengan membaca kumpulan cerpen Senyum Karyamin karya Ahmad Tohari secara intensif. Selanjutnya, penulis membaca buku-buku, jurnal, data internet tentang sastra khususnya cerpen, pendeskripsian karakter tokoh, dan macam-macam gaya bahasa. Selain itu, kegiatanberikutnya adalah mencatat setiap gaya bahasa yang terdapat dalam kumpulan cerpen tersebut dan mengelompokkan gaya bahasa yang mendeskripsikan karakter tokoh.

Mengacu pada uraian tersebut, pertanyaan yang dapat diajukan dalam penelitian ini adalah (1) Bagaimana cara menggambarkan karakter tokoh dalam kumpulan cerpen Senyum Karyamin karya Ahmad Tohari? (2) Bagaimana karakterisasi melalui gaya bahasa dalam kumpulan cerpen Senyum Karyamin karya Ahmad Tohari ? (3) Gaya bahasa apa saja yang dipakai Ahmad Tohari dalam menggambarkan karakter tokoh-tokoh dalam cerpennya? (4) Bagaimana implikasi penelitian ini bagi pembelajaran bahasa dan sastra di sekolah-sekolah?

\section{B. PEMBAHASAN}

Berdasarkan keempat pertanyaan tersebut, pemaparan hasil penelitian tentang karakterisasi melalui gaya bahasa pada kumpulan cerpen Senyum Karyamin karya Ahmad Tohari diuraikan sebagai berikut:

\section{Cara Penggambaran Watak dalam Kumpulan Cerpen Senyum Karyamin}

Dalam kumpulan cerpen Senyum Karyamin, pengarang melukiskan karakter tokohnya baik secara analitik (langsung) maupun dramatik (tak langsung). Hal ini dapat ditemukan dalam kutipan dari cerpen-cerpen berikut ini : 


\section{a. Cerpen Senyum Karyamin}

\section{1) Secara Analitik}

Karyamin sudah berpengalaman agar setiap perjalanannya selamat (Tohari, hal. 1).

...kata Sardi yang diam-diam iri pada istri Karyamin yang muda dan gemuk (Tohari, hal. 2).

\section{2) Secara Dramatik}

"Sudah, Min. Pulanglah. Kukira hatimu tertinggal di rumah sehingga kamu loyo terus, "kata Sardi... (Tohari, hal. 2).

“Jadi, kamu sungguh tak mau makan, Min?” tanya Saidah ketika melihat Karyamin bangkit.

"Tidak. Kalau kamu tak tahan melihat aku lapar, akupun tak tega melihat daganganmu habis karena utang-utangku dan kawan-kawan." (Tohari, hal. 4)

\section{b. Cerpen Si Minem Beranak Bayi}

\section{1) Secara Analitik}

Di bawah matahari wajah Kasdu kelihatan makin keras. Alis mata menyembunyikan sorot yang berat. Wajah Kasdu memperlihatkan bekas-bekas tempaan yang pahit. Dia kelihatan begitu tua. Padahal tahun hidupnya belum mencapai jumlah dua puluh (Tohari, hal. 12).

\section{2) Secara Dramatik}

Makin dekat ke rumah mertuanya, langkah-langkah Kasdu makin lambat. Bukan hanya karena lelah, tetapi terutama karena rasa bimbang yang mulai merayapi hari Kasdu (Tohari, hal. 14).

\section{c. Cerpen Blokeng}

\section{1) Secara Analitik}

Tetapi tentang si Blokeng memang tak ada duanya. Kecuali dia adalah perempuan yang secara biologis sempurna-seperti baru saja terbukti-sama halnya dengan perempuan-perempuan lain. Selebihnya, siapa pun tak 
sudi dibandingkan apalagi dimiripkan dengan Blokeng (Tohari, hal. 33).

\section{2) Secara Dramatik}

"Aku tak boleh berkata apa-apa. Kalau mulutku bocor dia akan memukulku dengan ini,'kata Blokeng sambil menggamit lampu senter pak hansip.

"Jadi ayah bayimu datang ke sarang ini membawa senter? Dia lelaki yang mempunyai senter?"

"Mbuh." (Tohari, hal. 35).

\section{d. Cerpen Orang-orang Pinggir Kali}

\section{1) Secara Analitik}

Ah, anak-anak orang di seberang kali itu juga sudah pintar bermain ayam (Tohari, hal. 53)

\section{2) Secara Dramatik}

"Ya. Tapi ya itu, Mas. Sekali Madrakum tetap Madrakum. Dia suka aneh-aneh saja," kata kang Samin sambil tersenyum.

"Kamu menertawakan saudara yang baru meninggal?"

"Maksudku bukan begitu. Aku hanya mau bilang, Madrakum suka aneh-aneh. Itu saja." (Tohari, hal. 55).

\section{Karakterisasi Melalui Gaya Bahasa dalam Kumpulan Cerpen Senyum} Karyamin

Dengan gaya bahasa, pemaparan imajinatif menjadi lebih segar dan berkesan. Hal ini seperti dikatakan Reaske (1966:33):

Figurative language: language which employs various figures of speech. Some examples are metaphor, simile, antithesis, hyperbole, and paradox. In general, figurative language is that kind of language which departs from the language employed in the traditional, literal ways of describing persons or objects. Using figurative language is making imaginative descriptions in fresh ways. It is usually immediately obvious whether a writer is using figurative or literal language. 
Karakterisasi dengan menggunakan gaya bahasa seperti metafora, simile, ironi, hiperbola dapat menambah kekuatan pada karakter tokoh cerita. Beberapa gaya bahasa tersebut dapat dijumpai pada kutipan cerpen-cerpen berikut ini.

\section{a. Cerpen Senyum Karyamin}

\section{1) Paradoks}

Pagi itu senyum Karyamin pun menjadi tanda kemenangan atas perutnya yang sudah mulai melilit dan matanya yang berkunang-kunang (Tohari, hal. 3).

Senyum yang sangat baik untuk mewakili kesadaran yang mendalam akan diri serta situasi yang harus dihadapinya. Sayangnya, Pak Pamong malah menjadi marah oleh senyum Karyamin (Tohari, hal. 6).

Kedua kutipan di atas mengontraskan keadaan Karyamin sehingga terlihat bahwa Karyamin adalah seorang yang menerima keadaan apapun tanpa beban, bahkan ia pandai menutupi situasi hatinya yang sedang susah. Namun senyuman itu terkadang menjadi lain artinya oleh orang lain yang selalu menilai sisi luar seseorang.

\section{2) Hiperbola}

Kali ini Karyamin tidak hanya tersenyum, melainkan tertawa keras-keras. Demikian keras sehingga mengundang seribu lebah masuk ke telinganya, seribu kunang masuk ke matanya. Lambungnya yang kempong berguncang-guncang dan merapuhkan keseimbangan seluruh tubuhnya. Ketika melihat tubuhnya Karyamin jatuh terguling ke lembah, Pak Pamong berusaha menahannya. Sayang, gagal (Tohari, hal. 6).

Dari gaya bahasa hiperbola tersebut, pengarang ingin menjelaskan bahwa Karyamin adalah seorang manusia yang mempunyai keterbatasan, ketidaksanggupannya menopang hidup yang demikian berat menekannya sehingga ia rubuh. 


\section{b. Cerpen Surabanglus}

\section{1) Personifikasi}

Laki-laki muda yang bingung itu keluar dari belukar. Lembah dan lereng yang terhampar di hadapannya tak memberi harapan apa pun (Tohari, hal. 18-19).

Gambaran lembah yang dapat bersikap seperti manusia menegaskan tokoh laki-laki muda tersebut semakin khawatir dan cemas.

\section{2) Metafora}

Bahkan didapatinya Suing dalam keadaan duduk di dekat perapian. Goyah dan wajahnya kembali menjadi topeng (Tohari, hal. 21).

Karakter tokoh dalam kutipan di atas digambarkan secara langsung dengan ciri yang melekat pada topeng yaitu datar, tak bereaksi, mati dan kaku.

\section{c. Cerpen Ah Jakarta}

\section{1) Metafora}

“Ceritanya mengesankan. Gali ya?”

"Seperti yang kamu dengar sendiri."

"Nah, awas kamu. Aku tidak ingin ada bangkai manusia yang pernah menginap di rumah ini.

Dari kutipan dialog tersebut muncul kata bangkai manusiayang melambangkan secara langsung dengan ciri yang melekat pada bangkai yaitu bau busuk, kotor, tak berguna, dan berbahaya bagi kesehatan.Gali atau preman sudah pasti dikenal oleh masyarakat sebagai seorang yang jelek kelakuannya bahkan sangat membahayakan dan harus disingkirkan.

\section{2) Sarkasme}

"Pekerjaan calo. Kemudian kusebut nama ngawur untukku. Alamat, kampung anu. Untung polisi tidak tanya KTP, suatu kecerobohan yang memalukan (Tohari, hal. 31). 
Dari kutipan di atas, terlihat sindiran tajam untuk polisi yang menginterogasi tokoh. Dengan sindiran tajam tersebut, pengarang ingin memberikan penjelasan bahwa polisi tersebut tidak teliti akan pertanyaan-pertanyaan yang diajukan.

\section{d. Cerpen Blokeng}

\section{1) Personifikasi}

Sampai Blokeng dengan selamat melahirkan bayinya dibidani nyamuk dan kecoa (Tohari, hal. 35).

Kutipan di atas menggambarkan bahwa Blokeng adalah seorang perempuan yang tangguh, perempuan pasar yang bisa mengurus dirinya sendiri hingga bisa melahirkan seorang bayi tanpa bantuan orang lain meskipun pada kenyataannya ia seorang yang terbelakang mentalnya.

\section{2) Simile}

Blokeng tidak mengerti apa itu polisi. Tetapi dia mengerti orang-orang berseragam yang pernah menarik tangannya agar dia menyingkir dari onggokan sampah pasar karena bupati mau datang meninjau pasar. Seperti monyet melihat belacan. Takut dalam citra satwa (Tohari, hal. 34).

Dari kutipan tersebut dapat diketahui bahwa Blokeng seorang yang mempunyai gangguan mental, tidak dapat berpikir dan perperilaku normal.

\section{e. Cerpen Rumah yang Terang}

\section{1) Personifikasi dan Simile}

Kampungku yang punya kegemaran berceloteh, seperti mendapat jalan buat berkata seenaknya terhadap ayah (Tohari, hal 43).

Gaya bahasa yang digunakan pengarang dalam kutipan di atas ada dua yaitu personifikasi dan simile. Kedua gaya bahasa tersebut menunjukkan bahwa warga kampung yang mempunyai kebiasaan menyebar gosip, tidak menyukai Ayah.

\section{2) Sarkasme}


"Tentu saja Haji Bakir tak mau pasang listrik karena tuyul tidak suka cahaya terang." (Tohari, hal. 44)

Kutipan tersebut berupa sindiran tajam yang ditujukan pada Haji Bakir yang tetap tidak mau memasang listrik sehingga warga kampung merasa terganggu dengan kegelapan di sekitar rumah mereka yang berdekatan dengan Haji Bakir. Karakter warga kampung yang salah menilai orang tanpa tahu alasan sesungguhnya atau warga kampung yang suka menuduh tanpa alasan yang jelas merupakan gambaran karakter yang bisa juga dijumpai dalam masyarakat kita.

\section{f. Cerpen Jasa-Jasa Buat Sanwirya}

\section{1) Sarkasme}

"Hore hore!" teriak Sampir. "Sekarang percuma memberi gelar pemuda onani pada Waras. Ia hebat. Hore hore!” (Tohari, hal. 10).

Gaya bahasa yang digunakan dalam kutipan di atas menunjukkan bahwa Sampir menyindir dengan kasar tokoh Waras yang pada akhirnya mempunyai keberanian bicara membela Sanwirya di depan teman-temannya.

\section{2) Ironi}

"Tapi kita tentukan dulu harga yang pantas untuk nyawa penderes itu."

"Bahkan itu terlalu tergesa-gesa. Kita buktikan dulu apakah tubuh Sanwirya juga digerakkan oleh nyawa. Kalau benar, nyawa kelas berapakah miliknya itu. Baru kita tentukan premi asuransinya."

Gaya bahasa yang digunakan dalam kutipan tersebut menunjukkan bahwa tokoh-tokoh yang berniat membantu atau merencanakan banyak jasa pada si penderes tidak tulus karena masih menilai, memperhitungkan nyawa seseorang berdasarkan status sosial, derajat orang tersebut di masyarakat. Hal ini juga 
merupakan fakta yang sering dijumpai dalam kehidupan masyarakat yang berkaitan dengan asuransi jiwa.

\section{Gaya Bahasa yang Digunakan dalam Penggambaran Karakter pada} Kumpulan Cerpen Senyum Karyamin

Kumpulan cerpen Senyum Karyamin karya Ahmad Tohari ini terdiri dari tiga belas cerpen. Ketigabelas cerpen tersebut adalah Senyum Karyamin, Jasa-Jasa Buat Sanwirya, Si Minem Beranak Bayi, Surabanglus, Tinggal Matanya Berkedip-kedip, Ah,Jakarta, Blokeng, Syukuran Sutabawor, Rumah yang Terang, Kenthus, Orang-Orang Seberang Kali, Wangon Jatilawang, dan Pengemis dan Shalawat Badar.

Dalam kumpulan cerpen Senyum Karyamin ini terdapat gaya bahasa metafora, hiperbola, personifikasi, simile, ironi, paradoks, dan sarkasme yang digunakan dalam penggambaran karakter tokoh. Jumlah gaya bahasa tersebut dapat dilihat dalam tabel di bawah ini:

Tabel Jumlah Gaya Bahasa dalam Karakterisasi pada Kumpulan Cerpen Senyum Karyamin

\begin{tabular}{|r|l|c|c|c|c|c|c|c|c|c|c|c|c|c|c|}
\hline No & $\begin{array}{c}\text { Gaya } \\
\text { Bahasa }\end{array}$ & SK & JJbS & SMBB & Srbl & TMB & AJ & Blkng & SS & RyT & Kth & OOSK & WJ & PdSB & Jumlah \\
\hline 1 & Personifikasi & 2 & 0 & 2 & 2 & 3 & 1 & 4 & 1 & 2 & 2 & 1 & 1 & 1 & 22 \\
\hline 2 & Simile & 0 & 0 & 1 & 2 & 2 & 1 & 2 & 1 & 2 & 3 & 3 & 0 & 4 & 21 \\
\hline 3 & metafora & 1 & 0 & 0 & 1 & 0 & 1 & 1 & 0 & 0 & 3 & 0 & 1 & 0 & 8 \\
\hline 4 & hiperbola & 5 & 0 & 0 & 0 & 3 & 0 & 1 & 0 & 0 & 1 & 0 & 0 & 0 & 10 \\
\hline 5 & Ironi & 3 & 3 & 0 & 1 & 1 & 0 & 3 & 7 & 0 & 4 & 0 & 1 & 0 & 23 \\
\hline 6 & Sarkasme & 0 & 2 & 0 & 0 & 1 & 1 & 0 & 0 & 4 & 0 & 0 & 1 & 1 & 10 \\
\hline 7 & Paradoks & 2 & 1 & 1 & 0 & 0 & 2 & 0 & 0 & 3 & 2 & 2 & 1 & 0 & 14 \\
\hline & Jumlah & 13 & 6 & 4 & 6 & 10 & 6 & 11 & 9 & 11 & 15 & 6 & 5 & 6 & 108 \\
\hline
\end{tabular}

Dari tabel di atas dapat diketahui bahwa gaya bahasa yang paling banyak digunakan untuk penggambaran watak tokoh dalam kumpulan cerpen Senym Karyamin karya Ahmad Tohari adalah gaya bahasa ironi dengan jumlah 23. Urutan-urutan berikutnya adalah gaya bahasa personifikasi berjumlah 22, simile berjumlah 21, ironi, paradoks 14, hiperbola 10, sarkasme 10, dan metafora berjumlah 8 .

Personifikasi yang ditampilkan untuk penggambaran karakter tokoh dalam kumpulan cerpen ini dikaitkan dengan alam sekitar tokoh. Misalnya, 
Lalu bagaimana mereka itu? Kok ada sebatang pohon jengkol yang tidak sudi menjadi tutup liang lahatnya. Sebatang pohon jengkol yang dipersonifikasikan demikian itu menegaskan penggambaran karakter orangorang (mereka) yang banyak dosa, sangat rakus akan apa saja.

Gaya bahasa simile digunakan untuk penggambaran karakter tokoh dengan cara membandingkan secara langsung hal-hal yang melekat pada sesuatu yang disebutkan pertama kali. Hal ini bertujuan untuk penegasan dan penguatan penggambaran tokoh. Misalnya, Tubuhnya menggigil, dingin seperti kodok.

Gaya bahasa ironi yang digunakan untuk penggambaran karakter ini bertujuan untuk memberikan sindiran halus tentang watak seseorang Misalnya, E, lha. Sabar Nak, sabar. Pertama, carilah kutu di kepalamu sendiri.

Gaya paradoks yang menggambarkan karakter tokoh menghadirkan suatu pertentangan dengan kebalikannya. Misalnya, dalam cerpen OrangOrang pinggir Kali. Untuk menegaskan karakter orang-orang pinggir kali, pengarang mempertentangkan dengan karakter orang-orang di lingkungan tokoh Aku seperti Begitu. Di sana kokok ayam jago, di sini seruan takbir. Di sini orang-orang pulang dari surau, di sana orang-orang jongkok sambil mengelus-elus ayam jago.

Hal melebih-lebihkan sesuatu atau dengan menggunakan gaya bahasa hiperbola ini bertujuan untuk penyangatan dalam menggambarkan karakter manusia. Misalnya dalam cerpen Kenthus, tokoh Dawet, istrinya tidak suka akan gaya pidato suaminya seperti Dawet merasa hampir muntah melihat gaya suaminya berpidato. Perutnya terasa mual.

Sarkasme dalam penggambaran karakter tokoh memberikan sindiran tajam secara langsung pada tokoh. Misalnya dalam cerpen Rumah yang Terang, "Sudahlah Nak. Kamu lihat sendiri, aku hampir mati. Sepeninggalku nanti kamu bisa secepatnya memasang listrik di rumah ini."

Gaya bahasa metafora dalam kumpulan cerpen ini digunakan untuk membandingkan secara tidak langsung dengan sesuatu yang masih mempunyai asosiasi makna. Misalnya dalam cerpen Surabanglus ini,Bahkan 
didapatinya Suing dalam keadaan duduk di dekat perapian. Goyah dan wajahnya kembali menjadi topeng. Kata "topeng" menunjuk pada bentuk wajah yang monoton, tak bereaksi, mata tak berkedip.

\section{PENUTUP}

Berdasarkan hasil penelitian dan pembahasan dapat disimpulkan bahwa (1) Karakterisasi melalui gaya bahasa dalam kumpulan cerpen Senyum Karyamin karya Ahmad Tohari membantu penggambaran watak tokoh menjadi lebih kuat, segar, dan berkesan; (2) Kuatnya gaya bahasa yang bernada sindiran, baik sindiran halus (ironi) maupun tajam (sarkasme) memberikan kekhasan cerita-cerita dalam kumpulan cerpen Senyum Karyamin sarat akan kritik sosial dan pesan kemanusiaan pada tokoh-tokohnya; (3) Kumpulan cerpen Senyum Karyamin mengajak pembaca untuk melihat ke bawah, dunia wong cilik dengan segala masalah kehidupan yang dihadapinya; (4) Kumpulan cerpen Senyum Karyamin mengajarkan pada pembaca agar selalu bersyukur dan senantiasa menjalin persaudaraan dengan makhuk ciptaan Tuhan sehingga tercipta kedamaian, keadilan, dan ketentraman di bumi ini.

\section{DAFTAR PUSTAKA}

Aziez, Furqonul \& Abdul Hasim. 2010. Menganalisis Fiksi. Bogor: Ghalia Indonesia.

Djojosuroto, Kinayati \& Noldi Pelenkahu. 2009. Teori Apresiasi dan Pembelajaran Prosa.Yogyakarta: Pustaka Book Publisher.

Fananie, Zainuddin. 2002. Telaah Sastra. Surakarta: Muhammadiyah University Press.

Luxemberg, Jan Van, Mieke Bal, dan Willem G. Weststeijn. 1992. Tentang Sastra. Jakarta: Gramedia.

Minderop, Albertine. 2011. Metode Karakterisasi Telaah Fiksi. 2011. Jakarta: Yayasan Pustaka Obor Indonesia.

Nurgiyantoro, Burhan. 2014. Stilistika. Yogyakart: Gajah Mada University Press.

Reaske, Christopher Russel. 1966.How To Analyze Poetry. New York: Monarch Press.

Sumardjo, Jakop \& Saini K.M. 1988. Apresiasi Kesusastraan. Jakarta: Gramedia. 
